UDK 78:168.522

Jurij Snoj

Znanstvenoraziskovalni center SAZU, Ljubljana

Scientific Research Centre of the Slovenian Academy of Sciences and Arts, Ljubljana

\title{
Tradicija humanistične misli in glasba
}

\author{
Humanities and Music
}

Ključne besede: zgodovina glasbe, dekonstrukcija, klasična glasba, glasboslovje, humanistika

\section{POVZETEK}

Postmoderni diskurz je pokazal nezaupanje do nekaterih osnovnih konceptov razumevanja zgodovine glasbe. $\mathrm{Z}$ zanikanjem obstoja temeljnih zakonov, ki naj bi usmerjali domnevno naravni razvoj glasbe, je dekonstrukcija podvomila $\mathrm{v}$ absolutne in neodvisne notranje vrednote, ki naj bi jih imela dela klasične glasbe. Ni naključje, da se je dekonstrukcija zgodovine glasbe pojavila v času, ko je z množico specialističnih študij vedenje o glasbi različnih zgodovinskih okolij naraslo do tolikšne mere, da se celotna zgodovina glasbe ne da več razlagati $z$ enim samim konceptom. Gledano s tega zornega kota je dekonstrukcija študij glasbe osvobodila od $\mathrm{v}$ preteklosti uveljavljenih vnaprejšnjih konceptov $\mathrm{z}$ njihovimi vrednostnimi sistemi in ideološkimi implikacijami. S postmoderno dekonstrukcijsko kritiko je zgodovino glasbe mogoče videti kot osvobojeno ideoloških vezi; taka pa je še vedno velika zakladnica znanja in razlag glasbe od antike do danes, zakladnica, ki nudi relevantno izhodišče domala vsaki novi študiji ali pristopu. V zvezi z naravo glasboslovja je pomenljivo, da se teorije in pristopi $z$ različnih humanističnih področij morejo aplicirati na glasbo. To je mogoče razložiti s podmeno, da glasba, čeprav je navidezno brez vsebine, ne nastaja neodvisno od svojega okolja; globoko je vkoreninjena v svojih kontekstih, istih,
Keywords: history of music, deconstruction, classical music, musicology, humanities

\section{SUMMARY}

The postmodern discourse has challenged some basic concepts of music history: by denying the existence of deep-laid laws that govern the purportedly organic development of music, deconstruction questioned the allegedly inherent absolute values of classical music works. It is not a mere coincidence, however, that the deconstruction of music history appeared at a time when due to highly specialized studies the knowledge of music in various historical environments grew to such an extent that it became hardly possible for the history of music to be interpreted by any single concept. Judging from this viewpoint, deconstruction seems to have liberated the study of music from preconceived and inherited theoretical notions and systems of values together with their ideological implications. Due to the postmodern deconstructive critique, history of music seems to have been liberated from conceptual and ideological bonds; as such, it may still be understood as a vast body of knowledge and interpretations of music from ancient times up to the present, offering a relevant starting point for as good as any new musicological study or approach. As for the nature of musicology, it is highly significant that theories and approaches from various areas of the humanities prove applicable to music. This fact may be explained by the hypothesis that music 
v katerih nastajajo tudi ostali izrazi človekovega duhovnega hotenja, ki so predmet humanističnih področij. Ker se koncepti $z$ drugih humanističnih področij morejo prenašati na glasbo, je glasboslovje v širšem smislu mogoče razumeti kot humanistični diskurz o glasbi.
- although seemingly without content - does not come into being independently of its environment; rather, it is deeply rooted in its contexts, the same that give rise also to other manifestations of the human spirit, eo ipso being subjects of the humanities. Since concepts from other aerias of the humanities may be applied to its subject, musicology in a broader sense of the word may be understood as humanistic discourse on music

Naslov današnjega simpozija nakazuje vprašanje: Kaj je glasboslovje v tokovih sodobnega globaliziranega sveta; je še vedno isto, kot je bilo pred štirimi desetletji? Prispevek skuša vprašanje osvetliti in nakazati možni odgovor. Teoretično izhodišče razpravljanja je hipoteza, da glasba ni nekaj, kar bi bilo zaprto samo vase in kar bi bilo neodvisno od vsega drugega, kar ni glasba, čeravno se na prvi pogled zdi takoob odsotnosti možnosti, da bi glasba kaj izrecno imenovala. Tako kot literatura, druge umetnosti, filozofija, vsi izrazi človekovega hotenja, je tudi glasba povezana $s$ tistim, kar jo obkroža; je zgolj delo ljudi v različnih zgodovinskih okoljih. To pomeni: njenega smisla ne moremo iskati le v njej sami, pač pa v kontekstih zunaj nje. ${ }^{1}$ Ker korenini v svetu zunaj sebe, je brez njega ni mogoče prav videti. Prav zato, ker je v njej nekaj, kar presega samo glasbeno zvočnost, je glasba, bodisi stara bodisi nova, torišče, na katero se morejo aplicirati misli, koncepti, ki so nastali in še vedno nastajajo zunaj nje. Glasba se razpira humanističnemu diskurzu v najširšem pomenu besede.

\section{Dekonstruirana naracija o zgodovini glasbe}

Glasboslovje je po definiciji veda, zato si ga je možno idealno misliti kot svobodno, zgolj spoznanja željno, brezinteresno, ideološko neobremenjeno in v tem smislu tudi neomejeno razpravljanje o glasbi in njeni zgodovini. A realno glasboslovje je drugačno. Če ga pogledamo s širšega zgodovinskega stališča, moremo videti, da temelji na takšnih ali drugačnih vnaprej postavljenih konceptih, prepričanjih, ki naj bi jih glasboslovno razpravljanje prepričljivo ponazorilo ali naj bi jih glasboslovna znanost celo dokazala in potrdila. Kot si ni težko predstavljati, imajo glasboslovni koncepti pogosto svoja ideološka ozadja ali jih je vsaj mogoče povezovati z njimi. Kaj je v ozadju glasboslovnega zanimanja, katera prepričanja ga usmerjajo, je najlaže razbrati iz glasbenih zgodovin kot bolj ali manj obsežnih in izčrpnih pregledov in sintez vsega glasboslovnega znanja. Tudi če v zgodovinskih pregledih koncepti in pojmovanja celote niso eksplicitno predstavljeni, so bolj ali manj jasno razvidni: bodisi iz kritiških opazk, ocen, splošnih povzetkov, uvodov v posamezna poglavja itd. Eden od najbolj splošno razširjenih konceptov pojmovanja glasbe $\mathrm{v}$ njenem časovnem razvoju je prepričanje o njenem napredovanju. Tako naj bi bila zgodnja, srednjeveška

\footnotetext{
1 Tomlinson, Gary, "The Historian, the Performer, and Authentic Meaning in Music", Authenticity and Early Music, ur.
} Nicholas KenYON, Oxford 1988, str. 135-136. 
polifonija naprednejša od koralnega enoglasja; Machautova dela naprednejša od notredamskih organumov; monodija s prehoda 16 . v 17. stol. kljub tehnični preprostosti naprednejša od polifone umetnosti druge polovice 16. stol. in pozni Bach naj bi bil navkljub tehnični dovršenosti v štiridesetih letih 18. stol. že zastarel. Tako gledanje vključuje misel, da je sedanjost najnaprednejša in da je prav to, kar je zdaj, točka, h kateri je težil stoletni razvoj. Drugi, tudi zelo razširjeni koncept pojmovanja zgodovine je prepričanje o tem, da ima vsako odbobje zgodovine svojega duha, ki se manifestira $\mathrm{v}$ vsem in $\mathrm{v}$ obliki sloga tudi $\mathrm{v}$ umetnosti in glasbi. Naloga glasboslovja naj bi bila odkrivanje duha dobe $\mathrm{v}$ glasbi, kar pomeni tudi raziskovanje zgodovine duha, kot se razkriva v umetnosti zvoka. Evropska glasbena romantika naj bi bila $v$ tem smislu kljub temu, da je neločljivo zraščena z glasbo druge pol. 18. stol., nekaj povsem drugega kot glasbeni klasicizem; temeljila naj bi na povsem drugačnem občutenju sveta in pogledu nanj. Zgodovine, ki so usmerjene v razlike med nacionalnimi kulturami in tiste, ki obravnavajo zgodovino glasbe določenega naroda, pa pogosto izhajajo iz vnaprejšnjega prepričanja o tem, da je dana glasba določljiva predvsem kot glasba določenega etnosa. Tisto, kar tako značilno loči F. Couperina od J. S. Bacha je potemtakem predvsem francoskost prvega. Kot naj bi imeli narodi, subjekti zgodovine, svoja pota in usode, tako naj bi imele svoja pota tudi nacionalne glasbene kulture. Ni si težko predstavljati, da so koncepti nacionalnih glasbenih kultur pogosto ideološko obarvani, včasih pa tudi neposredno odvisni od danih političnih razmer in tendenc.

Prikazanim konceptom bi mogli dodati še katerega; še zlasti bi jim mogli priključiti prepričanje in vero $\mathrm{v}$ veličino posamičnih glasbenih del oz. prepričanje o vrednotah, ki naj bi jih imela tradicija umetne, komponirane glasbe, tako imenovana klasična glasba. Po tem splošno razširjenem prepričanju naj bi v zgodovini nastajala glasbena dela, ki naj bi imela potrebe svojega časa močno presegajočo veljavo; dela, ki naj bi predstavljala absolutne, neodvisne vrednote, in sicer ne glede na to, ali so bila $\mathrm{v}$ svojem času napredna ali ne, ne glede na to, v katerem slogovnem obdobju so nastala in kateri nacionalni šoli naj bi pripadala. Zdi se, da je prepričanje o veličini posamičnih glasbenih del in tradicije klasične glasbe nasploh osmišljalo in še vedno osmišlja glasboslovno ukvarjanje $z$ glasbo. Osmišljalo je in še vedno osmišlja tudi spoznavanje tiste glasbe, ki naj bi ne bila tako pomembna, saj naj bi manj pomembne glasbene kulture in šibkejši skladatelji na neki način bodisi pripravljali pot velikim, ali pa naj bi njihove ideje $s$ svojimi sicer ne tako pomembnimi deli širili v druge prostore. $\mathrm{V}$ tej zvezi je pomenljivo, kako je bilo v 19. stol. razvijajoče se glasboslovje povezano $\mathrm{z}$ nastajanjem kanona del klasične glasbe in kako je raslo obenem z zavestjo o obstoju glasbe, ki naj bi imela trajno, nadčasovno veljavo. Kot vzorčni primer take glasbe so obveljali zlasti Beethovnovi opusi. Vse večje zanimanje za glasbo bolj oddaljene preteklosti, značilno za 19. stol., si je mogoče razlagati tudi kot poskus razumeti in videti dela velikih skladateljev 18. in 19. stol. v sklopu strnjenega in utemeljenega pogleda na celotno zgodovino glasbe; morda si ga je mogoče razlagati tudi kot poskus, odkriti véliko glasbo obdobij, ki vélike glasbe v smislu 19. stol. sicer niso poznala.

$\mathrm{V}$ zadnjih nekaj desetletjih so se v humanistični misli razvila gledanja, ki postavljajo tradicijo klasične glasbe in njene vrednote $\mathrm{v}$ novo luč, obenem s tem pa se na 
novo zastavlja vprašanje o glasboslovju kot vedi o glasbi na sploh in vedi o klasični glasbi posebej. Nova gledanja na klasično glasbo sodijo v postmoderni humanistični diskurz: razumevajo se kot postmoderna oz. izhajajoča iz mišljenja postmoderne dobe. Novim, postmodernim gledanjem na klasično glasbo in klasično glasbo spremljajoče glasboslovje je skupno predvsem to, da dvomijo o utemeljenosti miselnih podstati ustaljenega pojmovanja zgodovine in umetnosti in da te miselne podstati vidijo kot ideologeme v službi svojega časa.

Med postmodernimi gibanji je vidna in posebej zanimiva zlasti dekonstrukcija, ki je, kot priznavajo njeni zagovorniki, bolj diskurzivni proces kot pa teorija. Kot je znano, skuša dekonstrukcija pokazati, da stvari nehote same razkrivajo, da so ravno nasprotno od tistega, za kar se eksplicitno razglašajo. Dekonstrukcija je preizkušala in še preizkuša tudi sodobno muzikologijo in njene implicitne sisteme vrednotenja. Aplicirana na schenkerjansko glasbeno analizo je razkrila, da poteka schenkerjansko analiziranje $\mathrm{v}$ zaprtem krogu: Namen schenkerjanske analize je razkriti in prodreti $\mathrm{v}$ skrite in nedoumljive globine glasbenih del, ki so jamstvo njihove veličine; a metode schenkerjanske analize so izpeljane na glasbenih delih, ki so bila že vnaprej prepoznana za velika. Aplicirana na koncepte nacionalnih glasbenih kultur kot nosilcev glasbene zgodovine je dekonstrukcija skušala razgaliti njihove politične implikacije; za te se je izkazalo, da so prav $v$ nasprotju $z$ ideologijami demokracij druge pol. 20. stol. Slednjič je aplicirana na zgodovino glasbe dekonstrukcija skušala pokazati, da domnevnih ali celo izpričanih zakonitosti, ki naj bi usmerjale glasbeni razvoj, ni. ${ }^{2}$ Takšno spoznanje oz. gledanje pa vključuje dvom o domnevnih vrednotah klasične glasbe: Zanikanje pojmovanja, da je razvoj glasbe povezan in razložljiv, da ima zgodovina glasbe rdečo nit, je hkrati tudi zanikanje tradicije; a če zgodovine glasbe ni mogoče videti $v$ smislu tradicije, se pravi v smislu povezanega, pa čeprav včasih tudi zastalega razvoja, če ji ni videti smeri in smisla, so veliki glasbeni opusi postavljeni v zgodovinsko osamo; kot osamelci pa nimajo tistega leska, ki jim ga je dajalo gledanje, da pripadajo velikemu, tisočletnemu izročilu. Dvom v zakonitosti, ki naj bi usmerjale razvoj klasične glasbe, skriva tako v sebi dvom o njenih vrednotah.

Posvetimo se v nadaljevanju vprašanju dekonstruirane glasbene zgodovine. ${ }^{3} \mathrm{~V}$ zgodovinskih sintezah, tako manjših kot tudi večjih, je vedno nekaj, kar ostaja nepojasnjeno, česar zgodovinar ne more konsistentno razložiti, česar ne more spraviti $\mathrm{v}$ svoj pogled. Vse to zgodovinar odriva na rob svojega vedenja: v zgodovinskih prikazih so takšne stvari omenjane $\mathrm{v}$ drobnem tisku kot nekaj, kar je ob glavnem toku tudi obstajalo, ali pa so umeščene v opombe, ki naj jih bralec le ošine s pogledom ali pa tudi izpusti. Vse zgodovine, tudi obsežnejše, vsebujejo tudi vedenje o nečem postranskem, manj znanem, o nečem drugem, morda celo o nečem, o čemer

2 NORRIS, ChrISTOPHER, "Deconstruction", The New Grove, ${ }^{2} 2001$, 7, zlasti str. 124.

3 Med deli oz. razpravami, ki jih Norris navaja v zvezi z dekonstrukcijo zgodovine glasbe (Music and the Politics of Culture, izd. CHRISTOPHER NORRIS, New York 1989; NORRIs, CHRISTOPHER, Paul de Man, deconstruction and the critique of aesthetic ideology, New York 1988) ni nobene, ki bi se osredotočala izrecno na to temo. Drugačno, dekonstrukcijsko gledanje na zgodovino glasbe je sicer razvidno iz več mest v zborniku Music and the Politics of Culture: NorRIs, Christopher, "Utopian Deconstruction: Ernst Bloch, Paul de Man and the politics of music", str. 323-324; HiRsCHKOP, Ken, "The Classical and the Popular: Musical Form and Social Context", str. 295-296 (o nastanku koncepta glasbenega dela). 
naj bi sicer ne govorile; in s slednjo značilnostjo bi bile lahko šolski primeri dekonstrukcijskega branja.

Razumljivo je, da je tisto, kar je bilo na določeni stopnji glasboslovnega vedenja manj znano in morda tudi manj cenjeno, vzbujalo radovednost in vodilo $\mathrm{k}$ podrobnejšim raziskavam. Tako se je $\mathrm{v}$ drugi polovici 20. stol. zanimanje za glasbo raznih zgodovinskih okolij močno razmahnilo, zaradi česar je postajalo glasbenozgodovinsko vedenje vse večje in je danes nepregledno veliko. Med področji, ki so bila v drugi pol. 20. stol. deležna posebne pozornosti, je bila med drugim nezapisovana glasba, spoznavanje sledov katere je utrdilo zavest, da je poleg visoke skladateljske kulture, ki jo predstavlja komponirana in ohranjena glasba, v vsakem zgodovinskem okolju obstajala tudi druga glasba; dalje so bili posebne pozornosti deležni vmesni, dvolični, prehodni žanri - dvolični in vmesni le v očeh določene razlagalne sistematike, ki je imela vnaprejšnjo predstavo o stvareh, ki naj bi jih sistematizirala, in ki jo je naraščajoča zavest o drugih, domnevno obrobnih žanrih motila ali ogrožala; nadalje so se odkrivale in spoznavale stare izvajalske prakse, kar je marsikdaj povsem spremenilo ustaljene predstave o tem, kako je glasba izpred stoletij $\mathrm{v}$ resnici zvenela; ne nazadnje je bilo v 20. stol. odkrito veliko število pozabljenih repertoarjev in pozabljenih ali zamolčanih skladateljskih imen, med njimi tudi ženskih, in njihova odkritja so neredko vplivala na ustaljeni način hierarhičnega vrednotenja že poznanega. Ob rastoči zavesti, da je zgodovina glasbe nepregledno velika, je postalo glasbenozgodovinsko vedenje $\mathrm{v}$ drugi polovici 20. stol. tako obsežno, da more obstajati le še $\mathrm{v}$ obliki specializiranega znanja, ki se ne pusti razlagati $z$ enim samim konceptom. S stališča praktičnega obstoja glasboslovne vede to pomeni: Sodobni glasboslovci so lahko le specialisti, poznavalci določenega zgodovinskega okolja ali določenega aspekta glasbene zgodovine oz. glasbe; pravo strokovno poznavanje je lahko le poznavanje določenega dela celote. Prav zaradi tega je pogled na celoto, pojmovanje in motrenje glasbe v širših časovnih obdobjih, stopilo v ozadje in pojavil se je celo dvom glede strokovnosti takega pogleda. Ker je celota postala preobsežna, da bi jo bilo mogoče zaobjeti $z$ individualnim pogledom, je $\mathrm{v}$ zavesti poznavalcev komajda še prisotna. Posledično so obsežni zgodovinski pregledi, kakršnega podaja npr. Neues Handbuch der Musikwissenschaft, ${ }^{4}$ le še zbirka monografij ali esejev, ki so napisani vsak s svojega zornega kota, tako, da tistih esejev, ki govore o glasbi 18. stol., ni mogoče videti kot nadaljevanje monografije, ki govori o glasbi 17. stol.: kot da je glasba 17. stol. nekaj takega, kar zahteva povsem drugačen pristop in drugačno topiko kot glasba 18. stol., in kot da Leipzig, v katerem je deloval J. H. Schein, nima prave zveze $z$ Leipzigom J. Kuhnaua in J. S. Bacha.

A do dekonstrukcije zgodovine glasbe kot vede ni privedel le razmah glasbenozgodovinskega vedenja; spremljal jo je tudi sam metaglasboslovni diskurz: Obenem $s$ kopičenjem vedenja o glasbeni preteklosti je kritično, metaznanstveno branje časovno že odmaknjenih zgodovinskih sintez razkrilo, da so časovno že odmaknjene zgodovinske sinteze in njihovi razlagalni koncepti tudi sami del zgodovine. Tako se je

4 Ur. CARL Dahlhaus, Laaber-Verlag, Laaber 1989-1995. 
pokazalo, da je razmerje med zgodovino glasbe in njenimi razlagami prav obratno od navideznega: Zgodovine glasbe ni mogoče razložiti s takšnim ali drugačnim filozofskim ali ideološkim konceptom, pač pa je zgodovina glasbe tista, ki lahko pojasni tak ali drugačen razlagalni koncept, kar je le enačica splošno znane misli, da je vsaka razlaga zgodovine zgodovinsko pogojena. Orisani aspekt razvoja zgodovine glasbe oz. glasboslovja $\mathrm{v}$ zadnjih nekaj desetletjih napeljuje na misel, da se je glasboslovje dekonstruiralo samo, da je doživelo naravno, notranjo dekonstrukcijo, če jo smemo tako imenovati, in zgolj samoumevno in naravno je, da se je ob tem spogledalo $\mathrm{z}$ dekonstrukcijo kot postmodernim diskurzom.

Dekonstruirana zgodovina glasbe se tako kaže predvsem kot razpad misli, prepričanja, vere, da je smisel zgodovine glasbe spoznaven in da ga je mogoče videti in razložiti. To hkrati pomeni razpad prepričanja, da je zgodovino glasbe mogoče razlagati na način vsevedne pripovedi, ki jo piše vsevedni pripovedovalec, ki ve, kam vodijo zgodovinski tokovi in kaj je cilj zgodovine. Če si izposodimo termin iz literarne teorije, je dekonstruirana zgodovina glasbe le dekonstruirana naracija o glasbi; razvpita misel o koncu zgodovine je tako predvsem misel o koncu določenega pripovednega žanra. Z drugega, afirmativnega zornega kota je mogoče reči: Dekonstruirana zgodovina glasbe je pripoved o glasbi, lahko tudi narativna, ki je rešena bremena, da bi morala vse vedeti in znati vse razložiti; zaveda se, da je sleherni koncept hkrati, ko se rojeva, tudi sam zgodovina. Zaveda se, da se s pozitivističnimi metodami ne da dokopati do stvari, ki so onstran pozitivističnih tipalk. Morda je dekonstruirana glasbena zgodovina tudi upor proti prikritemu ali celo odkritemu diktatu, po katerem naj bi zgodovinarji dokazovali relevantnost takih ali drugačnih filozofskih in ideoloških konceptov zgodovine umetnosti. Če jo vidimo tako, potem je dekonstruirana zgodovina glasbe osvobojena bremena ideologije, ali se vsaj zaveda možnosti ideoloških implikacij katerega koli konceptualnega jedra.

\section{Zgodovina glasbe in sodobne glasbene prakse}

Pred štirimi desetletji še ni bilo aktualno vprašanje, katera glasba je tista, ki naj bi se ji glasboslovje posvečalo; splošno je veljalo, da je le klasična glasba vključno z njenim nadaljevanjem $\mathrm{v}$ sodobni čas tista, ki zaradi svojih notranjih vrednot zasluži raziskovalno pozornost. Ob klasični glasbi je uživala dolžno spoštovanje le še ljudska glasba, kot se je pojmovala v smislu folklorne tradicije. Danes ni redko prepričanje, da se veda ne bi smela omejevati na klasično glasbo, kar skoraj vedno pomeni tudi glasbo preteklosti ali vsaj glasbo, ki izhaja iz pretekle tradicije; slišijo se glasovi, da je glasboslovje na napačni poti, če ne odpre ušes za vse tisto, kar na različnih koncih globaliziranega sveta posluša na milijone in milijone ljudi.

Postavlja se vprašanje: Zakaj govori in razpravlja glasboslovje skoraj vedno le o glasbi preteklosti in zakaj se, kadar se usmerja v sedanjost, omejuje največkrat le na tako imenovano resno glasbo, ki nastaja iz pretekle tradicije in se nemalokrat vzdržuje le zaradi statusa pripadnosti resni, družbeno vsesplošno priznani glasbi? Ali ni ukvarjanje s preteklostjo beg pred sedanjostjo; ali ne bi bilo bolje ukvarjati se z glasbo, ki nastaja, se v resnici posluša in konsumira zdaj; ali ni tisto, kar nas obkroža, ne 
samo laže dostopno, pač pa tudi mnogo pomembnejše kot ono, kar je kdaj koli in kjer koli obstajalo? Nedvomno je obstoj sodobnih glasb tudi s stališča ukvarjanja $z$ glasbo preteklih obdobij upoštevanja vreden, saj se katera koli glasba - tudi tako abstraktna, kot so npr. nekateri na nobeno priložnost vezani Bachovi opusi - vedno posluša $\mathrm{v}$ realnih okoliščinah, določenih $\mathrm{z}$ vsem, ne nazadnje tudi $\mathrm{s}$ sočasno obstoječimi glasbenimi praksami. $Z$ drugimi besedami bi bilo mogoče reči, da je zanimanje za glasbo sedanjosti že vključeno v zavesti, da o smislu katere koli glasbe, tudi stare, soodloča ali celo izključno odloča njen vsakršni kontekst. A poleg tega se v svetu, kjer je vse hkrati dostopno in kjer je zato hkrati prisotno najrazličnejše, še posebej zaostreno postavlja vprašanje razmerja med različnimi glasbami. Sociološki pogled na glasbeno sodobnost prepričljivo vidi, da glasba ni brez ideološkega naboja in v tem smislu kljub temu, da ničesar ne imenuje, tudi ne brez vsebine. ${ }^{5}$ Ta pogled, ki zaradi stališča, s katerega motri glasbo, ne more videti bistvenih razlik med tradicijo klasične glasbe in katero koli zdaj obstajajočo živo glasbeno prakso, ${ }^{6}$ je upoštevanja vreden, saj s sociološkega zornega kota zelo zaostreno in celo izzivalno postavlja vprašanje o domnevnih posebnih vrednotah klasične glasbe. Še zlasti pa je vredno razmisleka postmoderno naravnano prepoznanje tako imenovane estetske ideologije, ki naj bi obvladovala glasbeno dogajanje v pretežnem delu 19. in 20. stol. in katere ideološko izhodišče naj bi bilo prepričanje, da je glasba prav s tem, da ne more ničesar pomeniti, privzdignjena in odmaknjena od vsega stvarnega in politično aktualnega. ${ }^{7}$ Misel na estetsko ideologijo je pomembna, saj terja ponovni premislek o nekaterih temeljnih aksiomih glasbene estetike. A kljub prepričljivosti prikazanih misli in gledanj ter naravnosti njihove pojavitve se zdi, da se vprašanje, kaj je klasično, preteklo in kaj sodobno ter aktualno, včasih poenostavlja.

Površinskemu pogledu je preteklost daleč, sedanjost blizu, sedanjost pomembna, preteklost pa bolj ali manj predmet zanimanja realnemu življenju odmaknjenih specialistov in njihovih strok. V tem smislu naj bi bila katera koli tema o sodobnem dogajanju $\mathrm{v}$ glasbi v bistvu pomembnejša kot pa npr. zasledovanje nenavadnega potopisa, ki ga je mogoče spremljati od Beethovnove prve do njegove zadnje klavirske sonate; nenavadnega $\mathrm{v}$ tem, da kljub razpoznavno ponavljajočim se temam ( $\mathrm{v}$ glasbenovsebinskem smislu) na svojem začetku ne daje nikakršne slutnje o tem, kje se bo končal. Gotovo je res, da je katero koli glasbo preteklosti treba odkriti; treba je priti do nje. Vendar ni res, da bi bil poglobljen vpogled v sedanjost kaj lažje izvedljiv. Pogledu, ki je globlje naravnan, misli, ki išče v globino, je sedanjost prav toliko oddaljena, kot ji je oddaljena katera koli preteklost. Še več kot to: Postmoderni diskurz se je odrekel iskanju smisla zgodovine. Prav s tem pa je zabrisal ali celo ukinil meje med preteklostjo in sedanjostjo. Če zgodovina nima razpoznavnega smisla, je vse preteklo relevantno na isti ravni kot vse

\footnotetext{
5 NORRIS, CHRISTOPHER, Music and the Politics of Culture, str. 7-9 ("Introduction").

${ }^{6}$ HIRSCHKOP, KEN, nav. delo, zlasti str. 298-303. Hirschkop prenaša Bahtinove teorije o poetičnih in novelističnih tekstih (kot jih je Bahtin pojmoval) in dialektični napetosti med njimi na področje glasbe, tudi sodobne. MATTHEws, DAVI, "The Rehabilitation of the Vernacular", Music and the Politics of Culture, izd. ChristopHER NorRIs, New York 1989, zlasti str. 245-251.

7 NoRRIS, CHRISTOPHER, Music and the Politics of Culture; estetska ideologija je eksplicitno označena med drugim na str. 9, 18 ("Introduction").
} 
sedanje. To pa pomeni: Zgodovina ni stvar od nas oddaljene preteklosti; niti ni pripoved o preteklosti, katere namen naj bi bil zlasti to, da bi osmišljala sedanjost in kazala pot v prihodnost. Bolj kot to je zgodovina vidik sedanjosti; je nekaj, kar kaže in opozarja na skrito stran tega, kar vidimo in slišimo okoli sebe. Postmoderna zgodovina glasbe, osvobojena vsevedne zgodovine, tako ne zakriva glasbene sedanjosti; prav nasprotno, videti jo je mogoče kot nekaj, kar odkriva njeno zakrito stran; je tisti vidik, ki omogoča, da glasbo sedanjosti bolj popolno slišimo, da vidimo na njej nekaj več, nekaj, česar sicer ne bi videli. Zaostreno bi bilo mogoče reči, da razkriva zgodovina glasbe tisti vidik glasbene sedanjosti, ki omogoča, da glasbeno sedanjost sploh slišimo. Prav zaradi tega je težko najti glasboslovno temo, ki ne bi imela svojega izvirnega in prvobitnega izhodišča v zgodovini glasbe. Seveda je takšna trditev sprejemljiva le, če v postmodernem smislu, brez ideoloških predsodkov, moremo videti, kaj dejansko pomeni ta termin, termin zgodovina glasbe, ki je prepogosto premalo jasno definiran in zato tudi zavajajoče poenostavljen.

Naj bo zamišljeno nekaj primerov: Glasboslovje se bo na svojem področju psihologije glasbe zelo verjetno še ukvarjalo z vprašanjem dojemanja tonalitetne osrediščenosti, ki je eden od ključnih fenomenov glasbe sploh; še zlasti se glasboslovje temu vprašanju ne bo moglo izogniti, če bo pojavu v smislu postmodernih teorij odreklo naravnost, organskost ${ }^{8}$ in ga gledalo le kot projekcijo družbe, organizirane okoli absolutne moči. A tonalitetna osrediščenost je nekaj, kar je v prvobitni podobi mogoče spoznavati $v$ glasbi čisto določenih razdobij, in izvirno vedenje o njej je zbrano in dostopno v doslejšnjem zgodovinskem glasboslovju. To vedenje bo relevantna in neobhodna oporna točka tudi za tista študijska prizadevanja, ki bodo skušala presojati tonalitetni osrediščenosti podobne pojave $\mathrm{v}$ glasbah neevropskih okolij. Enako se bo glasboslovje na področju estetike glasbe najbrž še ukvarjalo s problemom oblike $v$ glasbi. Ob tem se bo nujno vprašalo, zakaj se je vprašanje glasbene oblike začelo pojavljati zlasti v tistem času, ko se je začelo pojavljati tudi vprašanje glasbene vsebine. Od tod ne bo daleč do vprašanja, kakšna in kaj je bila glasba 19. stol., da se je vprašanje oblike in vsebine ostrilo prav ob njej. Nadalje si ni mogoče predstavljati, da nevmatski zapisi 10. stol. - nekaj, kar je kar najbolj oddaljeno od sodobnosti, ne bi bili zanimivi vsakomur, ki je o glasbi razmišljal s pojmi semiotične teorije: Kaj je zapisano nasproti slišanemu, mišljenemu, petemu, se kaže v nevmatskih zapisih na prvobiten način, in sicer zlasti zato, ker so nevmatski zapisi samonikel poizkus vzpostaviti znakovni sistem, ki bi ustrezal glasbi 9. stol. Še primer iz grške antike: Razmišljanju o Platonovi filozofiji glasbe gotovo nekaj manjka, če ni nobene predstave o tem, kakšno bi stvarno moglo biti tisto, kar je Platon imenoval "ta mele", ali kar so mu bile harmonije; a vedenje o tem je stvar zgodovine glasbe. Tudi če ubira razmišljanje o Platonovi filozofiji glasbe ali ukvarjanje $\mathrm{z}$ njo povsem nova pota, ne more obiti glasbenozgodovinskega toposa grške melike.

Ob razmišljanju o glasbi v časovni razsežnosti in dekonstruirani vedi o njej se nakazuje najširši odgovor na vprašanje, kaj je glasboslovno ukvarjanje z glasbo. Ne-

8 NORRIS, CHRISTOPHER, "Utopian Deconstruction: Ernst Bloch, Paul de Man and the politics of music", str. 324. 
dvomno je glasboslovje danes tako obsežno in razvejano, da najrazličnejšim prizadevanjem in smerem ni mogoče poiskati skupnega imenovalca. Morda so jedro glasboslovja glasbena vprašanja v ožjem smislu, vprašanja o tistem, kar je v glasbi neposredno otipljivo: tehnike komponiranja, njihov razvoj, izsledki glasbenih analiz, ki vodijo $\mathrm{k}$ abstrakcijam na različnih ravneh, se pravi k teoriji glasbe. Vendar je v glasboslovju vse to predmet najrazličnejših refleksij, in sicer bolj ali manj istih, kot vse druge umetnosti in druga opredmetenja ali izrazi človekovega hotenja: Pred slabimi štiristo leti je avtor ene od latinskih glasbenih poetik Joachim Burmeister v svojem delu razlagal glasbo z retorično teorijo; čeprav je bilo njegovo delo zgolj poetika, je vzorčni primer glasboslovja kot humanističnega diskurza o glasbi. Podobno je bilo, ko je Arnold Schering iskal v glasbi preteklih obdobij simbolno; ${ }^{9}$ tako je imenoval tisto, čemur bi kdo drug rekel duh časa in kar je bila le aplikacija Heglovega pojmovanja zgodovine kot zgodovine duha na zgodovino umetnosti. Zdi se, da danes, ko muzikolog slovečega imena skuša pokazati, kaj naj bi bil proces dekonstrukcije na primeru izbrane Bachove fuge, ${ }^{10}$ ni bistveno drugače. Dejstvo, da se misli, teorije, diskurzi z drugih področij morejo aplicirati na glasbo, je pomenljivo; očitno kaže, da glasba kljub temu, da ničesar ne imenuje, zaradi česar njene vsebine ni mogoče prevesti v besede, ni odmaknjena ali odločena od vsega ostalega, pač pa je na neki način povezana in zraščena s svojim okoljem. To hkrati pomeni, da vedenja o glasbi ni mogoče omejiti na kompozicijsko poetiko in njo spremljajočo teorijo: $\mathrm{v}$ glasboslovju se glasba odpira širokemu in iz desetletja $\mathrm{v}$ desetletje drugačnemu diskurzu humanistične misli.

\footnotetext{
${ }^{9}$ SCHERING, Arnold, "Musikalische Symbolkunde“, Vom musikalischen Kunstwerk, izd. Friedrich Blume, Leipzig 1951, str. 98-119.

${ }^{10}$ JosePH Kerman na 17. kongresu IMS v Leuvnu dne 6. 8. 2002.
} 